\title{
Reshaping the future of ethnobiology research after the COVID-19 pandemic
}

\author{
A geographically diverse group of 29 ethnobiologists addresses three common themes in response to the \\ COVID-19 global health crisis: impact on local communities, future interactions between researchers and \\ communities, and new (or renewed) conceptual and/or applied research priorities for ethnobiology.
}

\begin{abstract}
Ina Vandebroek, Andrea Pieroni, John Richard Stepp, Natalia Hanazaki, Ana Ladio, Rômulo Romeu Nóbrega Alves, David Picking, Rupika Delgoda, Alfred Maroyi, Tinde van Andel, Cassandra L. Quave, Narel Y. Paniagua-Zambrana, Rainer W. Bussmann, Guillaume Odonne, Arshad Mehmood Abbasi, Ulysses Paulino Albuquerque, Janelle Baker, Susan Kutz, Shrabya Timsina, Masayoshi Shigeta, Tacyana Pereira Ribeiro Oliveira, Julio A. Hurrell, Patricia M. Arenas, Jeremias P. Puentes, Jean Hugé, Yeter Yeșil, Laurent Jean Pierre, Temesgen Magule Olango and Farid Dahdouh-Guebas
\end{abstract}

T he public health crisis triggered by SARS-CoV-2, the cause of the COVID-19 disease, is teaching us that the world is no longer operating under the assumption of 'business as usual'. According to the online global tracker managed by Johns Hopkins University ${ }^{1}$, as of the end of May 2020, there are more than 5.8 million confirmed cases of COVID-19 across 188 countries and regions, a number that is still increasing. Undoubtedly, this global health crisis will also have a profound impact on the discipline of ethnobiology that is devoted to the interdisciplinary study of past and present relationships between humans, cultures and the biophysical environment, with a focus on knowledge, cognition and the traditional use of plants and animals.

Ethnobiology is primarily a field-based enterprise that has scholars and students 'on the ground' in diverse biological and cultural landscapes around the world. Ethnobiologists tend to travel frequently for fieldwork, often to remote and relatively isolated areas, interacting directly with local communities.

Much ethnobiology research is relevant to the conservation of biological and cultural diversity ('biocultural diversity') ${ }^{2}$, and directly relates to sustainability; in fact, along with its sub-discipline of ethnobotany, ethnobiology has been called the 'science of survival's.

Given the discipline's long-standing concern for addressing environmental and cultural problems, a key question is: how will ethnobiology reshape itself in a post-COVID-19 world? Twenty-nine ethnobiologists from seventeen countries reflect on how they envision the future of ethnobiology, addressing one major topic and its likely impact. The swift response from many colleagues who provided their views reflects a shared sense of necessity and urgency to carry out this exercise.

We opted to keep reflections as individual viewpoints because they are informed by local geographies that are shaped by specific political, social, cultural and economic contexts. As such, they represent opportunities for understanding either subtle or outspoken differences in scholarly opinions related to post-COVID-19 ethnobiology around the world. Moreover, ethnobiology's broad mission includes a diversity of research topics that are fittingly represented by these individual perspectives.

However, regardless of geographical and/or research-specific priorities, there are recurrent themes that tie these reflections together: (1) how the pandemic will impact local and indigenous communities, their traditional knowledge, livelihoods and use or management of natural resources; (2) how this crisis should guide future interactions between researchers and local communities; and (3) what the new (conceptual and/or applied) priorities of the discipline should be. Inevitably, there exists some degree of overlap between these themes (Fig. 1).

The impacts from the COVID-19 pandemic reveal both the strengths and weaknesses of ethnobiology as a discipline. Some reflections offered here are new, while others (for example, empowering local and indigenous communities or developing new plant-based medicines) have been largely confined to the readership within ethnobiology or its closely related fields. Now, with the pressure of the COVID-19 crisis in full force, the mainstreaming of these perspectives will become critical, especially given the discipline's stake in the conservation of, and sustainable and ethical use of, biocultural diversity ${ }^{4,5}$.

Common theme 1: how the pandemic will impact local communities, their traditional knowledge, livelihoods and use or management of natural resources

John Richard Stepp: shutdown of animal and insect markets. Clearly the world community is now going to view local 'wet markets' (markets that sell live and dead animal products for human consumption) with considerable scepticism and even disdain, since the likely origin of SARS-CoV-2 is zoonotic and a general public opinion has formed that the initial infection occurred in a market, although there is some evidence to the contrary ${ }^{6}$. These markets are rich sources of ethnobiological resources, knowledge transmission and knowledge production ${ }^{7}$. While government officials need to make sure that markets are not a public health nuisance, it is likely that overreactions will lead to the wholesale termination and destruction of markets in countries across the globe. There will be significant network effects from these actions that reverberate both to consumers and also back to local producers and communities. Consumers will be forced into further engagement with industrial food production systems, while producers will lose income and the ability to sell their products. In China alone, $30-59 \%$ of the food supply is procured in wet markets $^{8}$, and this is true in many 


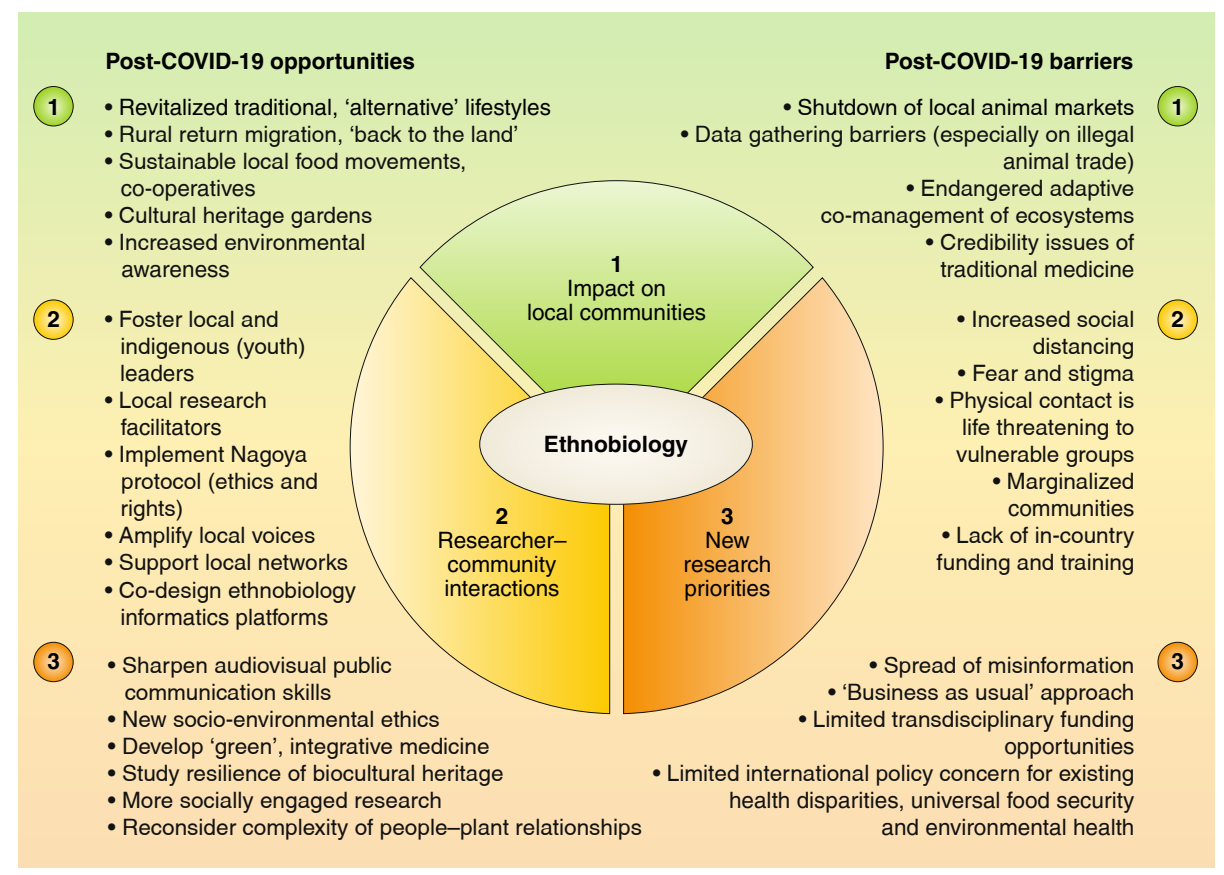

Fig. 1 | Schematic representation of three common themes in ethnobiology that were identified by a geographically diverse group of 29 ethnobiologists from 17 countries in response to the COVID-19 global health crisis. (1) Impact on local communities, (2) future interactions between researchers and local communities and (3) new (or renewed) research priorities for ethnobiology. For each of these common themes, there will likely exist opportunities after the COVID-19 pandemic, but also barriers.

other countries as well. Animal and insect markets often coexist with markets for food, medicinal and ritual plants, so there is likely to be an impact on wild and cultivated local food plant production systems as well.

\section{Rômulo Romeu Nóbrega Alves and Tacyana Pereira Ribeiro Oliveira: the COVID-19 pandemic, wildlife trade and use regulations, and ethnobiology} studies. The coronavirus (COVID-19) pandemic has provoked severe public health and socioeconomic impacts worldwide, hereby raising attention to animal-human interactions. The impacts extend to disciplines assessing these interactions, such as ethnozoology. A major focus of ethnozoology is studying the use and trade of wild animals, activities which are strongly linked with virus transmissions to humans. The current pandemic is expected to promote important changes in animal exploitation regulations, such as those imposed by China on 24 February 2020, which banned the hunting, trade, consumption and farming of all edible terrestrial wildlife. Undeniably, if not for the coronavirus outbreak, this ban would have hardly been adopted by a country with such strong cultural preferences toward the use of wild animals. Likewise, other countries may follow the Chinese legislation amendments. The legislation associated with wildlife exploitation is a crucial driver of the interactions between people and animals, and may imply difficulties in gathering ethnozoological data, primarily (illegal) trade data. This is an important issue to be considered when ethnozoological studies are pivotal in assessing animal trade and uses worldwide; for instance, by providing essential information on consumer demand, product source or destination, and trends in captures, prices and uses ${ }^{9,10}$. Conversely, an important role for ethnozoology following the COVID-19 crisis includes assessing conflicts that emerge from pandemic bans, hereby helping to promote dialogue between stakeholders (such as dealers, consumers and wildlife managers) and assessing shifts in trade and use of other animal groups not covered by the bans (that is, aquatic species), which will raise further conservation challenges.

Farid Dahdouh-Guebas and Jean Hugé: adaptive co-management and mere livelihoods endangered by COVID-19 confinement measures. Adaptive co-management brings together stakeholders linked somehow to the management of a social-ecological system $(\mathrm{SES})^{11,12}$. These stakeholders often differ in community origin, ethnicity, profession and age, and in the way they use, need and influence ecosystems. Adaptive co-management is built on short feedback loops and requires dialogue and knowledge exchange to co-identify problems and co-produce visions and actions that maintain the resilience of a SES in times of (global) change. However, live meetings, formal and informal consultations and knowledge exchange, decision-making processes and so on cannot easily be continued online in rural areas or in traditional systems. Next to technical issues (for example, network coverage, maintenance and electric power reliability), institutions underpinning adaptive co-management cannot simply be dematerialized and held online, at least not in the short run. This prompts the question: how adaptive is 'adaptive co-management', if vital co-management elements that occur 'live' are halted by confinement measures in view of an overriding public health crisis? Next to impeding dialogue and face-to-face contact, strict confinement measures have an even greater impact on people whose livelihoods directly depend on daily excursions to get water and food, such as people living in drylands, fishermen and so on. We must find a way to ensure that adaptive co-management is also resilient in the face of unexpected global crises, such as COVID-19. Inevitably, at some point, trade-offs need to be made by individuals left with the choice between respecting well-intentioned, top-down rules to protect society and public health, and focusing on day-to-day survival by fulfilling their individual and community needs.

Tinde van Andel: COVID-19 increases the demand for medicinal plants, while traditional healers lose credibility. The outbreak of the SARS-CoV-2 virus has increased the demand for medicinal plants, especially in heavily infected countries like China and the USA ${ }^{13}$. Medicinal plants like ginger and turmeric are marketed as 'immune boosters' that cure or protect against the coronavirus ${ }^{14}$. The Chinese government credits traditional Chinese medicine as having cured thousands of patients with COVID-19 during the outbreak and proudly promotes herbal medicine as an alternative therapeutic solution $^{15}$. Through (social) media, YouTube, TV and word-of-mouth, self-identified traditional healers argue that while Western doctors struggle to combat this new virus, they already know the cure, which they make using herbs from their own backyard or local markets ${ }^{16}$. As COVID-19 is a new disease for which there has been little time to experiment with plant-based cures, these 
claims give traditional healers and herbal medicine a bad name. Several herbs may effectively treat (the symptoms of) viral diseases like influenza ${ }^{17}$, but no research has been done yet on their effectiveness against the new SARS-CoV-2 virus. Still, the fear of this new disease and the absence of a cure or vaccine drives the global demand for medicinal plants to provide general health improvement and potential cures. Ethnobotanists have a key role to play in analysing these trends and explaining that, if public health is our concern, the potential beneficial or adverse effects of herbal medicine and the influence of alternative healers on healthcare-seeking behaviour should be taken seriously.

Shrabya Timsina: rise of the alternative in South Asia. As the surging movement of Dharmic patriotism encounters the COVID-19 crisis, the ethnobiological elements of Dharma in South Asia are attracting political and popular attention. The iconic yoga guru and Ayurved businessman Baba Ramdev drew criticism from health professionals for publicizing his 'finding' that ashvagandha (Withania somnifera (L.) Dunal) may ward off the virus ${ }^{18}$. The most emblematic ethnobiological stir, however, was that of the ridiculed prescription of bovine urine and dung as medicine $\mathrm{e}^{19}$. Ayurved works with a particular framework of bio-elements and diagnostic tools and, as such, anything, even excrement, can be rendered medicinal, depending on the patient's conditions. Thus, its cosmology interacts awkwardly with the secular need to scientifically prove its 'validity', which faces backlash from a section of society that labels it pseudoscientific quackery ${ }^{20}$, and it suffers from its association with right-wing nationalism ${ }^{21}$. Consumerism and politicization simultaneously promote and endanger this heritage. But, its emphasis on locally procurable ingredients, yogic lifestyle and clean environments contrasts with the centralized, financially restrictive and mechanical approach of subcontinental biomedicine, now overwhelmed by crowded hospitals and scarce drugs. The crisis demonstrates the ills of overurbanization, narrow diets and sedentary lifestyles that compromise the immune response. The virus' origin stories are promoting vegetarianism and the re-consecration of nature. With millions of labour migrants now unemployed and the volatility of globalization again exposed, the crisis may encourage a heritage-oriented 'back to the land' movement built on the importance of nature worship and minimalist agrarian living, which, if handled cleverly, could redefine what is currently categorized 'alternative medicine'.

Yeter Yeşil: ethnobiological knowledge and local income generation after COVID-19. In addition to publishing in scientific journals, ethnobiological data should, after analysis, be arranged and communicated in an accessible and understandable way to the people from whom such data were obtained. The public should also be warned about products that may pose a significant health threat, including the plant and animal products they use in cultural traditions. The outbreak of COVID-19 has revealed the importance of transmitting accurate information to the public clearly and effectively.

At the same time, the COVID-19 pandemic may lead people to consider immigration back to rural areas; that is, a lifestyle closer to nature. Previous to COVID-19, the declining labour demand in agriculture provoked high rates of migration from rural to urban areas in Turkey ${ }^{22}$. However, the pandemic has now inevitably halted life, especially in large cities, where large numbers of people with close interpersonal relationships are confined to small areas. As ethnobotanists, we need to design studies that consider and prioritize economic returns to the countryside, which, as a result, may help reverse migration caused by economic problems. In particular, the development of cooperatives and other sustainable local food movements can be supported rather than represent the dominant industrial food economy ${ }^{23}$ in order to generate extra income. Thus, local production helps to ensure that people have a self-sufficient economic structure, and ethnobiology can play a proactive role in supporting such initiatives.
Laurent Jean Pierre: roots redux - the importance of the 'Jaden Kwéyòl' and endangered ethnobiological knowledge in a post-COVID-19 world, and for mitigation and adaptation to climate change. With the current COVID-19 pandemic and predicted climate uncertainty, there is growing international concern for safe foods and medicines, food security, sovereignty, local livelihoods and sustainability. Now more than ever, it has become necessary to prepare to feed and self-medicate an increasing world population, which, according to 2019 United Nations population prospects, is projected to grow by $34 \%$, from 7.7 to 9.7 billion people, by 2050 . Therefore, it is essential for small Caribbean island states to focus on feeding their people, promoting self-administered primary

healthcare at the household level and simultaneously reducing high 'nutraceutical' (food and medicine) import bills without overexploiting the environment. Hereby, our endangered ethnobotanical knowledge and the indigenous language associated with the Creole Garden (Jaden Kwéyòl), which instructs on preparation procedures for self-medication and self-sustainability at the community level, is essential to maintain the biosphere and ethnosphere that constitute the true web of life ${ }^{24}$.

By its very nature, the Jaden Kwéyòl uses low or no inputs, encourages biodiversity and cultural diversity ('biocultural diversity'), and supports a healthy and varied $\operatorname{diet}^{25}$. More specifically, in times of global crises when people are quarantined or isolated to prevent the spread of infection, it is important to ask: (1) which insights and lessons can be learned from this agricultural medical heritage, and (2) how do we sustainably use and manage this cultural heritage for creating health and wealth vital to present and future generations? We postulate that the model of the Jaden Kwéyòl is replicable for many people in diverse geographical localities.

\section{Common theme 2: how the COVID-19 crisis should guide future interactions between ethnobiology researchers and local communities}

Andrea Pieroni: time for co-creating a new way of ethnobiological being, experiencing and living. The consequences of this pandemic, and the fears and social distance it has created, will transform the ways we interact with local (especially elderly) participants. More participatory research via local facilitators will be crucial, as well as a more robust use of online interacting tools. The panic that this pandemic is generating around the world will plausibly lead to a scarring stigmatization of cultural groups from countries heavily affected by the virus. Additionally, since the pandemic is (correctly) perceived as life threatening for aged community members and other vulnerable societal groups - who are often key study participants for ethnobiologists - face-to-face encounters will become more difficult. Therefore, this pandemic is challenging the meaning of 'being social'. Ethnobiology methods might need to reshape their ethos and become more 'situated'26; that is, 'embedded' in local lives. This can be a unique chance to rethink ethnobiology as a platform and as a process, and not merely as a scientific discipline. According to Nygren ${ }^{27}$, scholars "have been happy to highlight the indigenous point of view' and to see local people as producers 
of endogenous knowledge regarding natural resource management, cosmological theories and medical cures; however, less attention has been paid to the contested and hybrid character of such knowledge". Nygren argued that knowledge systems should be seen as negotiating processes involving multiple actors and complex power relations. Ecological 'knowing' and practice are collaborative concepts ${ }^{28}$. Scientists, environmentalists and local communities should co-create long term processes with different nuances of knowing and living, and collective experimentation.

Natalia Hanazaki: reshaping research with local people. .... and then, a new virus invisibly arrived, causing an illness against which no one had prior immunity, sometimes symptomless, but killing more people than we could have imagined... This story of COVID-19 is an old story. Now we can feel, watch and live a small part of the terror that assaulted so many Amerindian people for more than five centuries. This time we all share a lack of prior immunity, but in the long term, those without proper healthcare assistance will suffer most. COVID-19, spread worldwide through airplane travel by the upper classes, will disproportionately affect the poorest and marginalized, including indigenous peoples and local communities (IPLC). What can we do as researchers and global citizens? First, we need to demand proper healthcare assistance from governmental authorities for IPLC facing this new disease while understanding and respecting their cultural contexts. Second, we should support IPLC networks that share information, especially to those living in remote areas, via social media, radio and other technologies, about the need to quickly respond to this epidemic with IPLCs' own measures of social isolation and restriction of outsiders. Finally, as researchers, we need to increase our awareness of ourselves as potential vectors of COVID-19 and other diseases. We have the responsibility to learn from what is happening, to improve our understanding of complex networks connecting people and appreciate how different cultures perceive and interact with the biological world. Ultimately, the main focus of ethnobiology is to help us value the simplest and most important thing in life: being human.

\section{Narel Y. Paniagua-Zambrana and Rainer W. Bussmann: COVID-19 as incentive for the ethnobiology community to} finally implement the Nagoya Protocol. Although the ratification of the Nagoya Protocol on Access to Genetic Resources and Fair and Equitable Participation in the
Benefits from their Use in the Convention on Biological Diversity ${ }^{29}$ has brought a boost to the recognition of the rights of IPLC, their participation in ethnobiology research often is still fragmentary. In this scenario, COVID-19 might be an incentive to change that and give local participants the role they deserve - to not only be participants, but also investigators and co-authors. Rather than sending (mostly) Western students and researchers around the globe, COVID-19 might finally force the ethnobiology community to focus on training local community researchers so that they can conduct interviews in their own communities, and then to fully participate in data analysis and publication.

COVID-19 could well highlight the possible contribution of local communities to global health. Viruses of Coronaviridae also have a long history of infecting humans. However, the pathogenicity of viruses belonging to Coronaviridae are generally believed to be low. Hypothetically speaking, local communities residing in areas with prevalence of Coronoviridae vectors or reservoirs could have also developed plant-based remedies both for curative as well as preventive purposes. In globalized science, the knowledge that our counterparts share with us must be protected so that it cannot be appropriated by actors who did not participate in the original study for both scientific and commercial purposes, and the benefits of the research must include the repatriation of the data obtained. COVID-19 could be a trigger to finally achieve this.

\section{Arshad Mehmood Abbasi: COVID-19} and marginalized communities. Human beings, the most intellectual and influential creatures of this universe, have been ominously influenced by nature through the emergence of COVID-19. Although the emergence of an infectious disease is not a new test for human survival, nonetheless, the effects of COVID-19 in an era of contemporary scientific knowledge and technologies is frightening. This pandemic has not only traumatized humans and shaken the social, economic, cultural and religious bases of human life, but it is also redefining human attitudes towards natural resources. Although indigenous people and other communities in rural areas are economically marginalized, they represent a real hub of traditional knowledge. However, isolation caused by the COVID-19 pandemic has significantly influenced their robust socio-cultural and religious bonds. Consequently, the role of ethnobiologists is crucial to help them cope with post-COVID-19 circumstances and shape future strategies and policies.
However, without professional training and funding, this will be specifically challenging for those working in developing countries in collaboration with deprived and disempowered communities living in remote areas with deficient modern amenities. Incorporating these much-needed measures will facilitate better interactions among ethnobiologists and native people, and will also contribute to coping with such disasters in a more appropriate manner in the future.

\section{Janelle Baker and Susan Kutz: zoonosis and ethnobiological knowledge.}

Ethnobiology field research in 2020 has come to a halt as indigenous communities limit access to outsiders during the COVID-19 pandemic. Concurrently, communities are encouraging members to return to the land for food and social distancing. A likely and very positive outcome is a revitalized connection with family and the land and improvements to intergenerational transmission of knowledge, both of which will lead to stronger food security and sovereignty.

COVID-19, however, is not the first, and will not be the last, wildlife zoonosis to emerge from the human-animal interface with pandemic consequences ${ }^{30}$. Indigenous people, who retain an intimate relationship with wildlife as part of their physical and cultural well-being, are facing ongoing and amplifying risks of zoonotic diseases in an increasingly stressed world; yet, they are also part of the solution. Grounded in multi-generational knowledge and typically living in remote areas, indigenous communities are the first line of defence for recognizing changes in their ecosystems ${ }^{31}$.

In a COVID-19 world, the importance of co-production of knowledge, supporting indigenous educational opportunities and fostering indigenous ethnobiologists is paramount for biocultural diversity in remote regions ${ }^{32}$. Community youth can further this research collaboration and education, bridging the gap between indigenous and scientific knowledge, as they can learn and share information both online and in the bush. Armed with the right tools to gather and record indigenous knowledge, and with the right partnerships to translate this knowledge to action, indigenous communities become essential leaders in wildlife, human and environmental health surveillance.

\footnotetext{
Masayoshi Shigeta: change of person-'life' relationships (including with viruses) - meaning of domestication, social distancing and cultural proximity in a post-COVID-19 era. The physical distance between two (living and/or non-living)
} 
things is important in many disciplines, including ethnobiology. The study of domestication is defined as the mutual (symbiotic) interactions between two living things (organisms) that enhance the life value of each other. I have been studying human-plant relationships by looking at local knowledge related to ensete cultivation (including Ensete ventricosum (Welw.) Cheesman) in the southern part of Ethiopia. My focus has always been on the intimate relationships between two living entities. However, in the case of COVID-19, a killer virus and non-living entity, the case fatality rate (number of reported deaths per number of reported cases) is up to $13 \%{ }^{33}$. What is more, the mode of dissemination of this virus may cause worse calamities than the Great Plague and H1N1-type influenza. In the post-COVID-19 era, much stricter norms of public health behaviour are foreseen as a global standard, including maintaining social distancing at all times. Likewise, there are likely going to be changes in the indigenous mode of interacting with living (and/or non-living) things, and naturally the meaning of cultural proximity may (or may not change) qualitatively. As ethnobiologists, our new role can be to trace changes in the interactions that will occur after COVID-19, and to describe these phenomena. Another important question is how we as researchers can rebuild our interactions with local people, which should also be a part of our new research agendas.

\section{Temesgen Magule Olango: co-designing} post-COVID-19 ethnobiology in sub-Saharan Africa (SSA). The impact of COVID-19 will likely be pronounced in SSA, profoundly altering the lives and livelihoods of the rural and urban poor, including IPLC. The region is uniquely exposed to the global emergency because of weakly developed healthcare systems, scarcity of public health personnel and limited financial resources. Interactions between existing vulnerabilities and the COVID-19 pandemic would intensify damages to social, health and food systems. Societal strains accompanied by fears and uncertainties will lead to changes in behaviours and beliefs of people. A plethora of malpractices, myths, social stigmatizations and scepticism will linger, hindering dialogues and engagements. In fighting back against COVID-19 in all its dimensions, ethnobiologists should take their stake through proactive steps for shaping the future, including (1) highlighting the possible contributions of local communities and their less understood wild and cultivated natural foods, as well as eco-pharmacological environments for resilience of local and global food and health systems; (2) airing voices of disadvantaged IPLC for equitable rights for benefit sharing; (3) designing customized action frameworks for decentralized capacity building for local stakeholders; and (4) partnering for ethnobiology informatics platforms for informed decision making. Although many of these actions might be deemed overly time-consuming and an unnecessary drain on scarce resources, they remain necessary contributions for co-designing the future of changing socio-cultural environments and human relationships to natural resources in the wake of the post-COVID-19 pandemic in SSA.

\section{Common theme 3: what the new (conceptual and/or applied) priorities of ethnobiology as a discipline should be}

Ina Vandebroek: a revolution is needed in how we communicate and collaborate. The COVID-19 crisis shows a real need for better mainstreaming of scientific facts and important lessons learned from ethnobiology research to counter the spread of misinformation. This amplified communication strategy will also drive much-needed continued attention to urgent global challenges many ethnobiologists are studying, ranging from the worldwide decline in biological and cultural diversity to health disparities faced by immigrant communities in urban environments. Ethnobiologists are doing a great job of communicating to their peers. Now they will also have to sharpen their audiovisual communication skills to reach those outside the scientific community more effectively and more often.

In addition to better shaping the public dialogue, the post-COVID-19 world will hopefully also see a concerted action from ethnobiologists in advocating for increased funding for international and transdisciplinary collaborations, cutting across existing barriers in the social and natural sciences and across geopolitical boundaries $^{34}$. Unfortunately, in many countries, funding for these two divisions is still operating in parallel, with scarce cross-pollination. A similar limitation exists for geographical funding opportunities, which are too often restricted to predefined regions or countries. Such limitations significantly hamper joint ethnobiology research in today's globalized world. Collaborations between researchers and community members should also become more visible, so that community voices are increasingly heard instead of being interpreted by scientists. Breaking down these walls will require coordinated action. If the COVID-19 crisis is showing us that we are all connected, we should use this as an opportunity to communicate and collaborate more intensely than ever.

Ana Ladio: ethnobiology studies raised the alarm about the socio-environmental crisis and now provide a foundation for a new set of socio-environmental ethics. Ethnobiology has often been described as a naive science, and misunderstood to be a discipline that yearns for the old ways of the indigenous cultures of the world. One of our main focuses has been to study these cultures' health and food systems. These systems are based on self-sufficiency and agroecological concepts, and rooted in non-exploitative relational models (sensu ${ }^{35}$ ) with an ethical commitment to renewing natural cycles. Those who follow these relational models know without a doubt that their destiny is irrevocably connected to the destiny of Mother Earth. The COVID-19 crisis shows us that the ethnobiology research carried out in these communities provided an early warning to the current socio-environmental crisis. The main causes for this pandemic have been the imposition of unscrupulous global market logic based on actions such as the indiscriminate destruction of forests, the use of damaging agrochemicals in industrial agriculture and, in particular, the illegal trafficking of wild species. The lack of food and health autonomy in urban centres, with inhabitants who no longer relate to nature, makes these areas highly vulnerable in this crisis. Therefore, after COVID-19, ethnobiology should have a much stronger role to play, proclaiming loudly to the world the ethical guidelines to be followed, which we learned from the indigenous peoples ${ }^{36}$. Ethnobiology should be an essential instrument in this new stage, with a call to reflect and sustain, with scientific evidence, a new conception of human health interconnected with the sustainability of the biosphere.

David Picking and Rupika Delgoda: ethnomedicine fit for the twenty-first century - a post-COVID-19 perspective. The Caribbean, like many regions in the Global South, faces significant health inequalities and potentially catastrophic repercussions from the health and economic impact of COVID-19. The region does, however, benefit from its unique biodiversity and rich culture of ethnomedicine ${ }^{37}$. At this time, perhaps more than ever, it is imperative that these are fully developed for the greater good. Cuba, by example, is unique in the region in its development of 'green medicine', providing a compelling illustration of scientific and traditional medicine merging. Cuba's green medicine 
focuses on prevention before intervention, reducing reliance on pharmaceutical drugs and keeping medicine close to the communities it serves ${ }^{38}$.

Partnering collaboratively and equitably with communities and traditional knowledge holders continues to hold potentially valuable insights into many of today's health challenges. While nature-based searches have and continue to inspire the development of treatments for a wide range of diseases ${ }^{39}$, COVID-19 delivers an urgent call to prioritize funding and innovative research methods for traditional medicines. Examples include the use of systems biology and reverse pharmacology to improve and confirm the efficacy and safety of Argemone mexicana L., a traditional treatment for malaria in $\mathrm{Mali}^{40}$.

A post-COVID-19 world presents an opportunity for a reboot, a re-evaluation and a re-envisioning of healthcare, the development of medicines that come from and are available to those in the Global South, and the development of a green, integrated or ethnomedicine fit for the twenty-first century. highlight its biological and socio-cultural dimensions. In the advent of globalization, human travel, trade and transportation increased, and the outbreak of COVID-19 underscores the need to develop prevention protocols towards safeguarding public health. Pharmacological research done over many centuries aimed at developing new microbial vaccines has failed to develop effective preventive viral vaccines and effective antiviral therapies. The unique biology of viruses makes it difficult to develop viral vaccines, as some viruses have very high mutation rates. Therefore, collaboration between researchers is required to shed more light on COVID-19 and human-virus interactions. In ethnobiology research, ethnopharmacological insights and socio-cultural factors are all important in the management and control of the COVID-19 outbreak. Since COVID-19 is widespread and a major public health problem, it is important to understand the broader social and cultural contexts that contribute to the experiences of affected persons, their families and their communities, including the role of socio-cultural factors such as inequality, informal settlements, inadequate health care systems and cultural beliefs in the spread and/or prevention of the epidemic. This is particularly important in South Africa and other countries in sub-Saharan Africa, where rural and urban communities have historically faced different public health challenges. Socio-cultural factors often associated with rural communities include poverty, poor sanitation, illiteracy and social stigma of infectious diseases. Therefore, public health interventions aimed at combating COVID-19 should also address the socio-cultural factors associated with the rural-urban divide.

\section{Cassandra L. Quave: a new look at traditional health strategies in the aftermath of COVID-19. The rapid} emergence of COVID-19 has put a tremendous strain on Western systems of medicine across the globe, overwhelming healthcare personnel and medical supply chains, especially in urban centres. Strategies have been overwhelmingly reactive, rather than proactive, both in tracking and treating cases. Individuals with underlying chronic health conditions have been among those at greatest risk, highlighting the importance not only of chronic disease prevention, but also health promotion and maintenance. Across many cultures, traditional systems of medicine put great emphasis on proactive health measures rather than reactive critical care. Yet the scientific basis of many traditional medical interventions remains poorly understood; this includes pharmacological activities of foods and medicines, as well as the psychological impacts of ritual practices on health and well-being. Medicinal plants are fundamental to the pharmacopoeia of many traditional medical systems, and while an estimated 28,187 species have been documented for use in plant-based medicine ${ }^{41}$, most have not been evaluated using modern laboratory techniques. Ethnobiologists are poised to make important contributions to the documentation, evaluation and dissemination of traditional health strategies. Collaborations between scientists across diverse disciplines, including ethnobiology, chemistry, microbiology, pharmacology, psychology, immunology and more, can open up new paths to enriching medical resources and shifting paradigms towards more holistic care across the world. Moreover, ethnobiologists can serve as key connectors between local stakeholders and scientists, facilitating pathways for equitable access and benefit sharing. At a time when the public has lost much control over their health and well-being, the need for a deeper understanding of intercultural health paradigms ${ }^{42}$ has never been greater.

Guillaume Odonne: ethnobiology in motion - COVID-19 as a trigger to consider the dynamics and resilience of biocultural heritage. Local knowledge is never fixed, since cultural groups exchange, wage war, dissolve and reconstitute over time. Some groups experienced collapses, as did most of Americas' peoples in the past 500 years $^{43}$. Among those communities still surviving, a high biocultural resilience arose to radical change, and this must be understood as a major cultural trait ${ }^{44}$. Adaptation mainly concerns cultural relationships to changing ecosystems, but also to the pathosphere (the global panorama of surrounding pathogens), driving changes in people's religious, medicinal and sociocultural systems. The COVID-19 pandemic is a unique opportunity to switch from a fixist to a dynamic view of ethnobiological knowledge. Deciphering the mechanisms of changes in biocultural heritage might help to better understand these societies than through recording lists of species that become often obsolete in the next few decades, since medicinal floras worldwide are full of alien species ${ }^{45}$.

Documenting biocultural dynamics through time thus needs an urgent and long-term investment in fundamental research. As an example, during the last five years, the Teko people from French Guiana, with a population of $\sim 500$ people, lost $20 \%$ of their elders, which means a significant decrease in the biocultural heritage of this community. The COVID-19 pandemic, which particularly affects elderly persons, will likely erase a substantial part of humanity's biocultural heritage worldwide. It is therefore crucial to invest in its interdisciplinary and participatory inventory and to decolonize methods, so that research is conducted in an intercultural and respectful way, and towards mutual benefit ${ }^{46}$. Ethnobiology as an academic science owes this to local knowledge.

\section{Ulysses Paulino Albuquerque: towards} a more rigorous and socially engaged ethnobiological science. The community of ethnobiologists has long advocated more theoretical and methodological rigor in the research being carried out. The discussion about the dichotomy between quantitative versus qualitative research, for example, is already out of date. We concluded that we need to overcome the phase of traditional surveys to answer questions that are original, relevant and have some importance (whether theoretical or applied). In a post-COVID-19 world, these questions are even more important. Scientists will be increasingly demanded to produce relevant knowledge, either to advance science or to improve people's quality of life. The association of COVID-19, as well as other diseases, with human patterns of use of biodiversity (regardless of scale), poses 
significant challenges for ethnobiologists, such as (1) the planning and execution of studies on broad geographical scales; (2) the need to act more and more in cooperation, uniting different skills and expertise; and (3) the carrying out of the movement to unite knowledge from different areas of science through the active participation of different professionals. In a post-COVID-19 world, ethnobiologists will face major changes in social dynamics, which will influence field activities, migrations, emergencies and the re-emergence of diseases. Also, we will need to respond to other challenges that ethnobiologists should address, including climate change and its effects on biocultural diversity. The post-COVID-19 world makes the definitive invitation for ethnobiologists to review their research agendas.

\section{Julio A. Hurrell, Patricia M. Arenas and Jeremías P. Puentes: re-thinking ethnobiology - the challenges of} complexity. It is difficult to assess the impacts of the COVID-19 pandemic when we are still going through its evolution. However, several omens for the post-COVID-19 global scenario regarding health, social and economic aspects, among others, are discouraging. In this context of uncertainty, many local ethnobiological investigations have already encountered problems, especially with field work (interruption of surveys or loss of collaborators among others) due to the often mandatory quarantines affecting both researchers and collaborators. We have suspended our own work in urban ethnobotany with Chinese immigrants in the metropolitan area of Buenos Aires, Argentina. In recent years, pre-COVID-19, ethnobiology has shown an intense development of theoretical and methodological issues that were forcing a re-evaluation of the discipline, which has made evident the intrinsic complexity of ethnobiology's object of study, the web of relationships between people and their biological environments within the framework of biocultural systems. This implies, for example, re-thinking nature and culture as a unit (not as separate pathways), or re-considering interviews as communication systems that generate meaning (not as mere information exchange). This recursive reflection would help to give new meaning to ethnobiology after the COVID-19 crisis, which should not only be understood as a 'catastrophe' but as a 'decision' or 'critical judgment'; that is, an opportunity for change.

Ina Vandebroek (D) 1 ,

Andrea Pieroni (D)2, John Richard Stepp ${ }^{3}$,

Natalia Hanazaki ${ }^{4}$, Ana Ladio (D) 5 ,

Rômulo Romeu Nóbrega Alves (D),
David Picking 7 , Rupika Delgoda7,

Alfred Maroyi ${ }^{8}$, Tinde van Andel (D)',

Cassandra L. Quave ${ }^{10}$,

Narel Y. Paniagua-Zambrana",

Rainer W. Bussmann ${ }^{12}$, Guillaume Odonne ${ }^{13}$,

Arshad Mehmood Abbasi (D) 14 ,

Ulysses Paulino Albuquerque (D) 15,

Janelle Baker (D) ${ }^{16}$, Susan Kutz ${ }^{17}$,

Shrabya Timsina ${ }^{18}$, Masayoshi Shigeta (D) ${ }^{19}$,

Tacyana Pereira Ribeiro Oliveira (iD) 20

Julio A. Hurrell21, Patricia M. Arenas ${ }^{21}$,

Jeremias P. Puentes ${ }^{21}$, Jean Hugé22,

Yeter Yeșil ${ }^{23}$, Laurent Jean Pierre ${ }^{24}$,

Temesgen Magule Olango ${ }^{25}$ and

Farid Dahdouh-Guebas ${ }^{26}$

${ }^{1}$ Institute of Economic Botany, The New York

Botanical Garden, The Bronx, NY, USA. ${ }^{2}$ University of Gastronomic Sciences, Pollenzo, Italy. ${ }^{3}$ University of Florida, Gainesville, FL, USA. ${ }^{4}$ Universidade

Federal de Santa Catarina, Florianopolis, Brazil. ${ }^{5}$ Universidad Nacional del Comahue-CONICET, INIBIOMA, Bariloche, Argentina. ${ }^{6}$ Universidade Estadual da Paraíba, Campina Grande, Brazil.

${ }^{7}$ The University of the West Indies, Mona Campus, Kingston, Jamaica. ${ }^{8}$ University of Fort Hare, Medicinal Plants and Economic Development (MPED) Research Centre, Alice, South Africa. ${ }^{9}$ Naturalis Biodiversity Center, Leiden, the Netherlands. ${ }^{10}$ Department of Dermatology, School of Medicine, Emory University, Atlanta, GA, USA. ${ }^{11}$ Herbario Nacionál de Bolivia, Universidad Mayor de San Andrés, La Paz, Bolivia. ${ }^{12}$ Department of Ethnobotany, Institute of Botany and Bakuriani Alpine Botanical Garden, Ilia State University, Tbilisi, Georgia. ${ }^{13}$ LEEISA (Laboratoire Ecologie, Evolution, Interactions des Systèmes Amazoniens), CNRS, Université de Guyane, IFREMER, Cayenne, French Guiana. ${ }^{14}$ Department of Environmental Sciences, COMSATS University Islamabad, Abbottabad Campus, Pakistan. ${ }^{15}$ Laboratory of Ecology and Evolution of Social-Ecological Systems, Universidade Federal de Pernambuco, Recife, Brazil. ${ }^{16}$ Athabasca University, Athabasca, Alberta, Canada. ${ }^{17}$ Department of Ecosystem and Public Health, Faculty of Veterinary Medicine, University of Calgary, Calgary, Alberta, Canada. ${ }^{18}$ The Forest School at the Yale School of the Environment, New Haven, CT, USA. ${ }^{19}$ Graduate School of Asian and African Area Studies, Kyoto University, Kyoto, Japan. ${ }^{20}$ Universidade Estadual da Paraíba, João Pessoa, Brazil. ${ }^{21}$ Laboratorio de Etnobotánica y Botánica Aplicada (LEBA), CONICET, Universidad Nacional de La Plata, La Plata, Argentina. ${ }^{22}$ Open University of the Netherlands, Heerlen, the Netherlands. ${ }^{23}$ Department of Pharmaceutical Botany, Faculty of Pharmacy, Istanbul University, Istanbul, Turkey. ${ }^{24}$ Saint Lucia Archaeological and Historical Society (SLAHS), Castries, Saint Lucia.

${ }^{25}$ School of Plant and Horticultural Science, Hawassa University, Hawassa, Ethiopia. ${ }^{26}$ Department of (Organism) Biology, Systems Ecology and Resource Management, Free University of Brussels ULB-VUB, Brussels, Belgium.

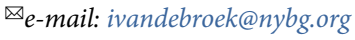

Published online: 22 June 2020

https://doi.org/10.1038/s41477-020-0691-6

References

1. Dong, E., Du, H. \& Gardner, L. Lancet Infect. Dis. 20, 533-534 (2020).

2. Maffi, L. Annu. Rev. Anthropol. 34, 599-617 (2005).

3. Prance, G. T. Econ. Bot. 61, 1-2 (2007).

4. Hunn, E. J. Ethnobiol. 27, 1-10 (2007).

5. Wolverton, S. Econ. Bus. Lett. 4, 21-25 (2013).

6. Huang, C. et al. Lancet 395, 497-506 (2020).

7. Kuhnlein, H. V. J. Ethnobiol. 34, 12-27 (2014).

8. Maruyama, M., Wu, L. \& Huang, L. J. Retail. Consum. Serv. 30, 33-39 (2016).

9. Alves, R. R. N., Silva, J. S., Chaves, L. D.S. \& Albuquerque, U. P. in Ethnozoology: Animals in our Lives (eds Alves, R. R. N. \& Albuquerque, U. P.) 481-496 (Elsevier, 2018).

10. Cooney, R. et al. Conserv. Lett. 10, 367-374 (2017).

11. Hugé, J. et al. J. Environ. Manage. 183, 988-997 (2016).

12. Plummer, R. et al. Ecol. Econ. 140, 79-88 (2017).

13. Caspani, M. U. S. Coronavirus threat fuels demand for traditional herbal remedies. Reuters https://www.reuters.com/article/ us-health-coronavirus-usa-herbs/u-s-coronavirus-threat-fuelsdemand-for-traditional-herbal-remedies-idUSKBN20W2GR (2020).

14. Suherdjoko. Semarang herbalists develop Jamu Corona to boost immune system. The Jakarta Post https://www.thejakartapost. com/news/2020/03/22/semarang-herbalists-developjamu-corona-to-boost-immune-system.html (2020).

15. Mai, J. \& Lo, K. Beijing pushes traditional Chinese medicine as coronavirus treatment despite questions over benefits. South China Morning Post https://www.scmp.com/news/ china/society/article/3076500/beijing-pushes-traditional chinese-medicine-coronavirus (2020).

16. Langa, P. L. We spoke to a traditional healer about Covid-19. CityPress https://city-press.news24.com/Trending/ we-spoke-to-a-traditional-healer-about-covid-19-20200327 (2020).

17. Li, T. \& Peng, T. Antiv. Res 97, 1-9 (2013).

18. Ulmer, A. Indian guru's tips to ward off coronavirus anger health professionals. Reuters World News https://www.reuters.com/ article/us-health-coronavirus-india-ayurveda/indiangurus-tips-to-ward-off-coronavirus-anger-healthprofessionals-idUSKBN21515M (2020).

19. Siddiqui, D. Hindu group offers cow urine in a bid to ward off coronavirus. Reuters World News https://www.reuters. com/article/us-health-coronavirus-india-cow-urine-pa/ hindu-group-offers-cow-urine-in-

a-bid-to-ward-off-coronavirus-idUSKBN2110D5 (2020).

20. Beall, J. Int. J. Womens Dermatol. 2, 115-116 (2016).

21. Khalikova, V. R. South Asia: J. S. Asian Stud. 40, 105-22 (2017).

22. Öztürk, M., Topaloğlu, B., Hilton, A. \& Jongerden, J. J. Balk. Near East Stu. 20, 513-530 (2018).

23. Anderson, C. R., Brushett, L., Gray, T. W. \& Renting, H. JAFSCD 4, 3-9 (2014).

24. Davis, W. The Wayfinders: why Ancient Wisdom Matters in the Modern World (House of Anansi Press Inc., 2009).

25. Degras, L. Le Jardin Créole, Repères Culturels, Scientifiques et Techniques (Éditions Jasor Archipel Des Sciences, 2005).

26. Nazarea, V. D. (eds). Ethnoecology: Situated Knowledge, Located Lives (Univ. of Arizona Press, 1999).

27. Nygren, A. Crit. Anthropol. 19, 267-288 (1999).

28. Whyte, K. P. Ecol. Process. 2, 7 (2013).

29. About the Nagoya Protocol. Convention on Biological Diversity https://www.cbd.int/abs/about/ (2015).

30. Daszak, P. Lancet 380, 1883-1884 (2012).

31. Kutz, S. \& Tomaselli, M. Science 364, 1135-1137 (2019).

32. North American Regional Declaration on Biocultural Diversity: The Atateken Declaration https://www.cbd.int/portals/ culturaldiversity/docs/north-american-regional-declarationon-biocultural-diversity-en.pdf (2019).

33. Oke, J. \& Heneghan, C. Global covid-19 case fatality rates. CEBM https://www.cebm.net/covid-19/global-covid19-case-fatality-rates/ (2020).

34. Jahn, T., Bergmann, T. \& Keil, F. Ecol. Econ. 79, 1-10 (2012).

35. Muradian, R. \& Pascual, U. Curr. Opin. Env. Sust. 35, 8-14 (2018). 36. Rozzi, R. Environ. Ethics 34, 27-50 (2012).

37. Vandebroek, I. \& Picking, D. Popular Medicinal Plants in Portland and Kingston, Jamaica (Pear Tree Press, 2016).

38. Escalona Arranz, J. et al. in Therapeutic Medicinal Plants: From Lab to the Market (eds Duarte, M. C. T. \& Rai, M.) 174-187 (CRC Press, 2015)

39. Newman, D. J. \& Cragg, G. M. J. Nat. Prod. 83, 770-803 (2020). 
40. Simoes-Pires, C. et al. Int. J. Parasitol. Drugs Drug Resist. 4, 338-346 (2014).

41. Alkin, B. in State of the World's Plants 2017 (Ed. Willis, K. J.) 22-29 (Royal Botanic Gardens, Kew, 2017).

42. Vandebroek, I. J. Ethnopharmacol. 148, 746-754 (2013).

43. Clement, C. R. et al. Proc. R. Soc. B. 282, 20150813 (2015).

44. Fernández-Llamazares, Á. \& Reyes-García, V. in Introduction to Ethnobiology (eds Albuquerque, U. P. \& Alves, R. R. N.) 69-74 (Springer, 2016).
45. Pieroni, A. \& Vandebroek, I. Traveling Cultures and Plants: The Ethnobiology and Ethnopharmacy of Human Migrations (Berghahn Books, 2007).

46. Armstrong, C. G. \& McAlvay, A. C. J. Ethnobiol. 39, 3-13 (2019).

Author contributions

I.V. conceived the idea for the paper, analysed and visualized the contributions, and wrote the paper. A.P.,
J.R.S., N.H., A.L., R.R.N.A., D.P., R.D., A.M., T.v.A., C.L.Q, N.Y.P.-Z., R.W.B., G.O., A.M.A., U.P.A., J.B., S.K., S.T., M.S., T.P.d.O., J.A.H., P.M.A., J.P.P., J.H., Y.Y., L.J.P., T.M.O. and F.D.-G. wrote the paper.

Competing interests

The authors declare no competing interests. 